\title{
The General Practice 'Management of Otitis Externa'
}

\author{
Maj D G Robertson \\ $M B, C h B(E d), D C H, R A M C$ \\ General Practice Vocational Trainee*
}

\author{
Maj J D C Bennett \\ FRCS, DCH, RAMC \\ Senior Specialist ENT +
}

Department of ENT Surgery British Military Hospital Rinteln, BFPO 29

SUMMARY: Clinical confusion, treatment failure and recurrence commonly plague the Management of Otitis Externa. The aim of this study was to investigate the clinical attitudes and habits of army general practitioners and to review the recent literature. The results of a questionnaire survey showed that although all the respondents agreed that aural toilet was important, only $50 \%$ felt confident in performing aural toilet and packing. There also appeared to be much greater윽 scope for the use of astringents and effective preventative measures in addition to aural tiolet. The discussion emphasises and need for careful selection of the most appropriate topical agent, whilst highlingting the roles of practical proce? ures, bacteriology and prevention. A practical guide to diagnosis and management is offered with the aid of illustratiops? and an algorithm.

\section{Introduction}

Otitis externa (OE) is a common problem, and a general practitioner can expect to see some 16 new cases per year (1) with up to 10 per cent of the population being affected at some time in their life (2). Predisposing factors include pre-existing skin disease such as eczema, prolonged or repeated exposure to swimming water, both contaminated (3) and clear (4), and trauma to the external auditory meatus. All these are aggravated by hot climates, as illustrated by the reported frequency of $\mathrm{OE}$ in the Middle and Far East of 60 per thousand per annum during the Second World War (5). Previous literature has largely established the relative values and efficacy of certain key aspects of therapy. However, more recently, questions have been raised regarding awareness of these fundamentals and the effectiveness of current management policies $(6,7)$. The present study was undertaken to examine the attitudes and habits of a large group of Army GPs using a questionnaire based on accepted clinical keystones $(6,8,9,10)$. The discussion compares the results with current opinion and reflects on the advantages and disadvantages of the available range of topical ear preparations available for the treatment of OE.

\section{Methods}

A postal questionnaire was sent to all the general practitioners in the catchment area of the British Military Hospitals at Rinteln and Hannover; both are served by the Rinteln Ear, Nose and Throat (ENT) department.

* Now Vocational Trainee, Garrison Medical Centre Catterick Garrison

North Yorkshire.
+ Now ENT Registrar,

Queen Elizabeth Military Hospital Woolwich

London.

Replies were received from 51 out of 70 practitioners (response rate $74 \%$ ) in a total of 21 medical centres $\frac{0}{N}$ Views were sought in particular on topical ear preparas tions and the role of practical aural procedures.

Results

Eighteen different types of ear preparations were suggested. Nine doctors suggested only one substance, 24 indicated two and 18 had three choices. Antibioticsteroid drops were the commonest first choice, being reported in 45 out of $51(89 \%)$ cases. Astringents (three), quinolones (two), and a coal tar-steroid mixture (one) were the other primary selections. Astringents and antibiotic-steroid drops appeared somewhere in the overall choices of five $(10 \%)$ and fifty $(99 \%)$ of the doctors respectively. The commonest agent was Gentisone-HC drops, suggested by forty separate doctors $(79 \%)$.

There was universal agreement that aural toilet was a key aspect of management. Despite this only twenty-six $(51 \%)$ of respondents felt able to perform aural toilet. Some $33 \%$ of vocational trainees and $80 \%$ of doctors $₹$ with ENT experience were confident in this procedure, 음 while twenty-nine $(57 \%)$ felt able to insert an ear wick. Of the latter fourteen $(\mathbf{4 8 \%})$ used glycerine and ichthammol as a soaking agent, while steroid and anti- $\bar{N}$ biotic mixtures and aluminium acetate were the other $\sigma$ preferences of twelve $(41 \%)$ and three $(11 \%)$ respective- $\mathcal{N}$ ly. Twenty doctors $(39 \%)$ felt that ear swabs and $\underset{\omega}{N}$ bacteriology were important in the initial management 0 
of $\mathrm{OE}$. Amoxycillin and ampicillin were the commonest oral agents suggested (by twenty-six), when antibiotics were indicated. Flucloxacillin (seventeen), erythromycin (four), cephradine (two) and co-trimoxazole (two) were the others. Twenty-four respondents $(\mathbf{4 7 \%})$ gave practical advice against recurrence, thirteen suggesting astringent and/or alcohol drops. Simple drying of the ear (five), olive oil (one), sodium bicarbonate (one), antibiotic-steroid drops (one), and ear plugs (one) also appeared.

\section{Discussion}

\section{Pathophysiology}

Disruption of the natural self-cleansing mechanism of the outer ear and its antibacterial cerumen is frequently the initiating factor $(11,12)$. This is usually caused by a mixture of environmental and local physical factors. For example, a regular swimmer's ear may become itchy and is then irritated with a matchstick head. This leads to secondary inflammation or sensitisation (the chrome in the matchstick head) with subsequent invasion by microorganisms. McKelvie and McKelvie found that almost $60 \%$ of one group of OE sufferers admitted poking or scratching their ears with various implements (13). Fiftyeight different types of $\mathrm{OE}$ have been described (8) and there have been a number of popular synonyms such as hot weather ear, swimmer's ear, swimming pool ear, tropical ear, and Singapore ear. Several classifications exist but perhaps the simplest is to consider two main groups: reactive: (ineluding skin disorders, allergy and sensitisation to chemicals and ear drops) and infective (bacterial, fungal and viral) (14). Subgroups contain several specific forms such as herpetic or psoriatic $O E$, but the most common presentation is that of a diffuse of non specific form. There is a wide spectrum of severity, ranging from mild itchy lesions to the distressingly painful oedematous cases requiring intensive inpatient treatment. Treatment failure may be due to bacterial resistance, lack of aural toilet or use of hygroscopic agents (15), sensitisation to topical chemicals or antibiotics, failure to identify or remove causative factors (16), and secondary otomycosis. A detailed initial history and skilled use of the various therapeutic options will minimise such failures.

\section{Practical Procedures}

Aural toilet remains fundamental to the successful management of $\mathrm{OE}$ in the presence of any significant discharge. Most authors regard aural toilet as a keystone in the successful management of $\operatorname{OE}(7,10,17,18,19,20)$. There is almost unanimous agreement that mopping debris from an inflamed meatus not only speeds up resolution but facilitates clear otoscopy and the exclusion of perforation or chronic underlying middle ear disease $(15,20)$. There are still those who remain unenthusiastic about aural toilet (21), but this is very much a minority view and based on rather negative conclusions $(22,23)$. In our study those practitioners with postgraduate ENT experience were much more likely to feel confident in performing aural toilet. Overall only half the respondents felt able to perform this procedure and this figure seems unacceptably low to the authors, but it may be the result of today's increasing climate of subspecialisation, more open inter-referral between partners and the pressure of time. It could be argued that general practitioners should be equally adept at using a Jobson Horne probe as they are with a vaginal speculum and the taking of a cervical smear. This is an area of clinical territory which the doctor and practice nurse could share very effectively. However, it is vital that sufficient expertise is first gained and the condition not made worse (16). The overall conclusion seems to be that when OE is accompanied by debris or discharge, then the best results are achieved by using aural toilet and ear drops; the nature of topical agent appears to be of secondary importance to the action of the cleaning (20).

\section{Topical Therapy}

Our results showed a clear preference for antibioticsteroid drops as first line therapy. The most popular choice was Genticin HC drops. Part of the reluctance to employ astringent drops, such as aluminium acetate, more often probably stems from their old fashioned image and poor marketing. Patient expectations and deficiencies in postgraduate ENT training may be con tributory factors. The good reputation of antibiotica steroid ear drops stems from their safety, effectiveness and acceptability. However they are relatively expensive (Table 1). There is also a significant incidence of bacterial resistance (24), secondary otomycosis and iatrogenic skin problems (25). All these can create chronic or refractory $\mathrm{OE}$ and difficulty with subsequen management. A recent study examining chronic $\mathrm{OE}$ found that $68 \%$ of cases were sensitised to topical antibiotics, and this was increased when mixed preparations

Table 1

League Table of Topical Otic Preparation Costs

\begin{tabular}{|c|c|c|}
\hline Name & Antibacterial (S) & $\begin{array}{c}\text { Approx. } \\
\text { cost } \\
\text { per5ml }\end{array}$ \\
\hline Otomize & Neomycin & $£ 3.95$ \\
\hline Otosporin & Neomycin, Polymixin & $£ 3.92$ \\
\hline Audicort & Neomycin & $£ 2.93$ \\
\hline Sofradex & Framycetin, granicidin & $£ 2.75$ \\
\hline Framycort & Framycetin & $£ 2.21$ \\
\hline Gentisone HC & Gentamicin & $£ 2.00$ \\
\hline Cidomycin & Gentamicin & $f 0.84$ \\
\hline Locorten Vioform & Clioquinol & $£ 0.70$ \\
\hline Betnesol - N & Neomycin & $\mathfrak{f} 0.68$ \\
\hline $\begin{array}{l}\text { Aluminium Acetate } 8 \% \\
\text { BPC }\end{array}$ & & $\mathcal{f 0 . 5 8 *}$ \\
\hline $\begin{array}{l}\text { Aquaear (Australia) } \\
\text { Boric Acid 4\% BPC } \\
\text { Acetic Acid 5\% BPC }\end{array}$ & astringents & $\begin{array}{l}\mathfrak{f 0 . 5 0} \\
\mathcal{L} 0.27^{*} \\
\mathfrak{£ 0 . 2 6 ^ { * }}\end{array}$ \\
\hline Acetic Acid $\supset \%$ BPC & & $20.20^{\circ}$ \\
\hline
\end{tabular}

(* includes cost of a 25 pence container) 
were used (26). The quinolones, framycetin, gentamicin and chloramphenicol have been implicated (27) but the main culprit is neomycin, and it has been advised that it is not used in topical therapy (28). It has, however, been shown that when middle ear infection is also present all pathogens were sensitive to gentamicin (29). For this reason topical aminoglycosides, such as gentamicin, continue to be used by ENT specialists, supported by the monthly index of medical specialities (MIMS) (30). General Practitioners are sometimes reluctant to follow this trend (6), despite the absence of any correlation between topical aminoglycosides and sensorineural deafness (31). Although our findings show that the use of astringents is much less popular than antibiotics there is no scientific reason for this choice. Most research supports the use of simple astringents as first line therapy in uncomplicated diffuse $\mathrm{OE}(9,20,32)$. A recent comparison of aluminium acetate and gentamicin found that astringents were much cheaper (Table 1), caused negligible sensitation or bacterial resistance, and were just as effective (24). Although aluminium acetate $8 \%$, boric acid 4\% (in alcohol) and acetic acid 5\% (in alcohol) can all be made available, there are no proprietary stringent preparations available in the current MIMS. Locorten Vioform is the nearest compromise, being a topical antiseptic. In Australia, where OE is more common, at least two formulations (Earclear and Aquaear) are available "over the counter" and are effective in prevention or early treatment (33). Both preparations contain acetic acid and ispropyl alcohol which create a combined antimicrobial and hygroscopic effect. This was demonstrated in a study of swimmer's ear, where a five minute exposure to $5 \%$ acetic acid was bactericidal to all common pathogens of the external auditory meatus (34). Workers examining the efficacy of the new optic spray, Otomize, admitted that the acetic acid component probably had a significant influence on the clinical results (21).

\section{Bacteriology}

Twenty respondents $(39 \%)$ felt that ear swabs were important in the initial management of $\mathrm{OE}$. These are likely to reveal a predominance of Pseudomonas species, Staphylococci, coliforms, Proteus species and anaerobes (35). However sterile culture can account for a quarter of results (13). In tropical climates Aspergillus and Candida fungi are still the commonest cultures (36). It has already been found that bacteriological studies are best deployed in a secondary manner for refractory or recurrent cases $(4,9,32)$. Amoxycillin and ampicillin were the most favoured systemic antibiotic agents, the typical indication being severe $\mathrm{OE}$ with marked pain, oedema and cellulitis. However neither possesses activity against most strains of Staphylococcus aureus, which is the most likely pathogen in such cases (19). Flucloxacillin or erythromycin are more suitable choices.

\section{Prevention}

Prevention is a particularly important, though often unaddressed, component of the management of OE. Effective advice was offered by 19 respondents $(37 \%)$. The principles of prophylaxis include avoidance of trauma, good personal hygiene, control of skin disorders, maintenance of a dry meatus and identification of other causative factors. Hygroscopic spirit drops have been advised for swimmers $(10,37)$. Contraindications to drops containing alcohol include grommets, a perforated ear drum and broken skin. A rolled up pre-injection swab, such as Steret, which is impregnated with $70 \%$ isopropyl alcohol is useful, though as with all astringents a transient mild burning sensation is common (20). Where earplugs are prescribed it has been shown that cotton wool and paraffin BPC is the best waterproofing agent (38). Ear packs soaked in antibiotic ointments can also prevent active infection deteriorating in committed watersports competitors (11). "Blow drying" with a standard hair dryer is another practical suggestion (39). Perhaps the final word on prevention should go to Jones who used a similar formulation to Aquaear (5\% acetic acid in $85 \%$ isopropyl alcohol) and reported eight years of unbroken success in the prevention of swimmer's ear in the southern USA (37).

\section{Diagnosis and Management}

An overall management approach is shown in the algorithm (Fig 1). The history should identify any rele $\mathbb{8}$ vant predisposing factors, which include regularo swimming, poking of the ear, exposure to contaminate inland waters, skin disorders, allergy, foreign bodye travel and the wearing of occlusive hearing devices Sensitising agents such as topical antibiotics and drops for ear wax should be excluded. During examination the stigmata of specific forms of OE must be sought (8). At some stage otoscopy should be adequate enough to exclude serious underlying middle ear disease. Pain or discomfort of varying intensity is usual and may be elicited, typically by gentle manipulation of the tragus. This sign is not present in otitis media (11). Itchy icthyotic meatal skin reflects chronic cases; discharge is common in acute cases. The "discharging ear" per se is a distinct entity, however, and its various other causes must first be excluded (7). Local soft tissue swelling, deafness, tinnitus and distressing pain may all accompany the more severe cases. Once the diagnosis is made it is the severity and presence or absence of discharge which tend to direct treatment. Mild or chronic lesions tend to be "dry" and either "peripheral" or "deep". The former commonly occur in association with skin disorders and allergies. Cream and ointments appropriate to the primary cause are easiest to apply; Fucidin, Bactroban or Vioform $\mathrm{HC}$ are useful against any secondary bacterial infection. "Deep" meatal inflammation is best reaced by ear drops. Aluminium acetate $8 \%$ or boric acid $4 \%$ in $25 \%$ spirit are good choices in uncomplicated cases, although topical steroid drops may be needed for some chronic "reactive" lesions. The tragus should be . 




$($ CSOM $=$ Chronic Serious Otitis Media. OE $=$ Otitis externa; SYST $=$ Systemic $)$

Fig 1. Otitis Externa Algorithm 
pumped to ensure even distribution of drops (40). More florid lesions with debris will benefit from aural toilet. Although suction equipment is undoubtedly less traumatic, mopping of debris with a Jobson Horne probe and cotton wool can be equally effective (17). Horsefall gives a nice summary of equipment for examining and treating ear problems, including useful addresses (41). The basic principles of aural toilet are summarised in Figure 2. Swabbing should be carried out

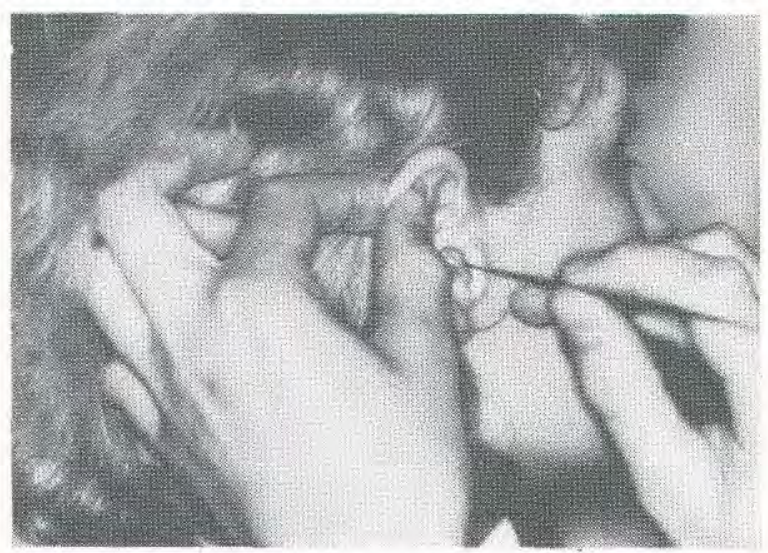

Fig 2. Aural Toilet

1. Gently pull the tragus backwards and upwards to straighten the canal.

2. Carefully swab the discharge in a rotary fashion for a few seconds.

3. Check progress with an auriscope and repeat as required with a fresh cotton wool pledget.

in a gentle rotary fashion for a few seconds only. Progress should be checked with an auriscope and the process repeated. Severe cases usually require strong

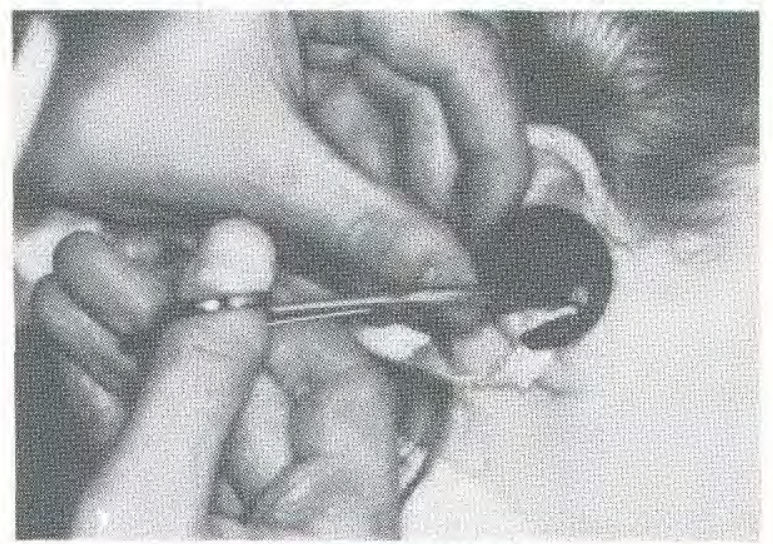

Fig 3. Packing of the Ear

1. Soak a length of ribbon gauze in an appropriate medium (see text).

2. Gently carry the gauze to within about half a centimetre of the ear drum using dressing or crocodile forceps.

3. Repeat the process, packing the ear with gentle pressure in a pleated fashion. analgesia, an ear wick and sometimes systemic antibiotics. Packing of the ear is illustrated in Figure 3. With the aid of packing forceps a length of ribbon gauze soaked in the treatment medium can be gently introduced deep into the ear canal until it is packed. This action tends to splint the canal and relieve pain. The packing may be changed after one to three days but some authors leave it in place up to a week (42). Commercially available foam wicks may be preferred by practitioners who do not feel confident about the traditional ear wick (19). Glycerine and ichthammol was used frequently in our study - it is soothing and has not only astringent but also hygroscopic properties; aluminium acetate $8 \%$, antibioticsteroid mixtures and Betnovate-C scalp lotion have all been advocated. With refractory cases it is important to exclude a missed specific $\mathrm{OE}$ or some persistent aetiology. It is also possible that a secondary otomycosis or bacterial resistance may have developed. At this stage a bacterial swab is recommended and positive cultures can be treated with the correct antimicrobials. However both fungal and bacterial growths usually respond to aural toilet and astringents - Pfleiderer considers that topical antifungals are rarely indicated (9). Preventive measures are worth consideration. Acetic acid $5 \%$ in $85 \%$ isopropyl alcohol is an effective preparation for swimmers and in chronic cases. Ear plugs can also be useful.

\section{Conclusion}

Otitis Externa is a common problem, particularly in hot climates and in swimmers. Lesions with debris are best treated with a combination of aural toilet and earô drops. It appears that the well-marketed antibiotic-? steroid preparations are still the preferred choice in first line therapy and that although cheap, effective and recommended, astringents are underemployed. Ear swabs can be useful in refractory cases but not at the outset of treatment. Systemic antibiotics, when indicated, should be effective against staphylococci.

\section{REFERENCES}

1, BURKE N. The Diagnosis and Management of the Discharging Ear, Practitioner $1989 ; 233,742-746$.

2. CAssi N, Cohn A, Davidson T, WITten B R. Diffuse otitis externa: clinical and microbiological findings in the course of a multicentre study on a new otic solution. Ann Otol Rhinol Laryngol 1977; 86: 1-16 suppl.

3. Weingarten M A. Otitis Externa Due to Pseudomonas in Swimming Pool Bathers. J R Coll Gen Pract 1977; 27: 359360 .

4. Wright D W, Alexander J M. Effects of water on the bacterial flora of swimmers' ears. Arch Otolaryngol 1974; 99,15-18.

5. ACKROYD R. Newer Topical Antibiotics in Otitis Externa, $J$ Laryngol Otol 1959; 73: 544-554.

6. Bickerton R C, Roberts C, LitTle J T. Survey Of General Practitioner's Treatment Of The Discharging Ear. Br Med J 1988; 296: 1649-1650.

7. Bain J, Williamson 1. Treating the Discharging Ear in Practice. Br Med J 1988: 296: 1617.

8. Scott Brown's Textbook of Otolaryngology. London. Butterworth 1987 vol 3 p53-59. 
9. Pfleiderer A G. Otitis externa. Update 15 Nov 1988; 902 908.

10. Jobbins D. Otitis Externa. Aust Fam Physician 1986; 15: 720-726.

11. Bell D N. Otitis Externa. Postgrad Med 1985; 78: 101-106.

12. BAllenger J J. Keratin and Cerumen Antibactrial Action. ed Hall I S, Coman B H. Diseases of the Nose, Throat and Ear. White Plains New York. Longman 1976 p781.

13. McKelvie M, McKelvie P. Otitis Externa. Br J Dermatol 1966; 78: 227.

14. Mawson S. Diseases of the Ear. London. Arnold. p224.

15. Hicks S C. Otitis Externa: Are We Giving Adequate Care? J $R$ Coll Gen Pract 1983; 33: 581-583.

16. McDowall G D. External Otitis - Otological Problems. $J$ Laryngol Otol 1974; 88: 1-13.

17. Brooks D. How to Perform Aural Toilet. Update 15 Oct $1988 ; 717-721$.

18. EDITORIAL. Eardrops. Lancet 1976;1: 896.

19. Reilly P G. Otitis externa: the case for thorough aural toilet. Modern Medicine. 1991; 36: 227-228.

20. SLACK R W T. A Study Of Three Preparations In the Treatment Of Otitis Externa. J Laryngol Otol 1987; 101: 533-535.

21. SMITH R B, MoodiE J. A general practice study to compare the efficacy and tolerability of a spray Otomize versus a standard ear drops formulation Sof radex in the treatment of patients with otitis externa. Curr Med Res Opin 1990 12: $12-$ 18.

22. Morton R A D. Neomycin undecylenate and triamcinolone acetonide in the topical tratment of otitis externa. Southwest Med 1970; 51:84-86.

23. BAIN D J G. A double-blind comparative study of Otoseptil ear drops and Otosporin ear drops in otitis externa. J Int Med Res 1976; 4: 79-81.

24. Clayton M I, Osborne J E, Rutherford D, Rivron R P. A double blind. randomized, prospective trial of a topical antiseptic versus a topical antibiotic in the treatment of otorrhoea. Clin Otolaryngol 1990; 15: 7-10.

25. CALNAN C D, SARKAANY I. Contact dermatitis from Neomycin. Br J Pharmacol 1958; 70: 435-445.
26. SMITH I M, KLAY D G, BuXton P K. Contact hyper-sensitivity in patients with chronic otitis externa. Clin Otolaryngol 1990; 15: 155-158.

27. Peterkin G A G. Otitis Externa. J Laryngol Otol 1974; 15 21

28. Jensen C O, Allen H J, Mordecai C R. Neomycin contact dermatitis superimposed on otitis externa. $J$ Am Med Assoc $1966 ; 195: 175$.

29. KILNCOYNE A G. Gentamycin-hydrocortisone eardrops in chronic inflammation. Practitioner 1973; 211: 91-92.

30. Monthly Index Of Medical Specialities (MIMS UK) 1990;

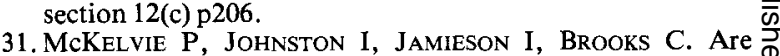
Eardrops Hazardous In Man? Br JAudiol 1975; 9: 45.

32. LAMBERT I J. A Comparison Of The Treatment Of Otitis Externa With Otosporin And Aluminium Acetate. $J R$ Coll Gen Pract 1981; 31: 291-294.

33. Monthly Index of Medical Specialties (MIMS Australia) 1989 section 13 (a) p168.

34. Jones E H. Does Acid pH Inhibit Bacterial Growth In The External Ear Canal? Laryngoscope 1961; 71: 928-936.

35. KeOGH C, Russel B. The Problem of Otitis Externa. Br Med J 1956; 1: 1068-1072.

36. Yehia M M, Al-Habib H M, Shebab N M. Otomycosis: a $\vec{\omega}$ common problem in Iraq. J Laryngol Otol 1990; 104: 387389.

37. Jones E H. Prevention Of Swimming Pool Ear. Laryngoscope 1971; 81: 721-733.

38. ROBINSON A C. An evaluation of waterproof ear protectors in swimmers. J Laryngol Otol 1989;103: 1154-1157.

39. HANDS B W. Blow Drying For Otitis Externa. Can M Assoc J 1987; 137: 1077.

40. Stewart I A. Topical Antibiotics In Otitis Externa. Med $J 1986 ; 99: 816$.

41. HoRSFALL $T \mathbf{J}$ M. Instruments for examining the ear. $U$ date 1981 ; 10: 895-905.

42. BLACK B. Practical Procedures: Use Of The Ear Wick. Aust Fam Physician 1986; 15: 805-806. 